\title{
RESPIRATION OF GREEN AND CHLOROPHYLL-DEFICIENT TYPES IN MAIZE ${ }^{1}$
}

\section{Miriam Georgia Groner}

THE PURPose of the experiments described in this paper was to study respiration in green and albino corn seedlings, as influenced by light and darkness, by anaerobic conditions, and by feeding different sugars to plants under conditions of carbohydrate starvation. Seedlings of an albino type make excellent material for respiration experiments because their respiratory rate can be accurately measured in light as well as in darkness.

The recessive nature of pure white plants has been demonstrated conclusively by Emerson (1912). These plants are characterized by the complete absence of chlorophyll, and normally perish within two or three weeks. The plants used were examined for plastids and none were observed, although some may have been present in a primordial condition. Matsuura (1929) states that there are at least ten genes for white seedlings, $w_{1}-w_{10}$. Five of them are simple Mendelian genes which are independently inherited, four of them form two sets of duplicate genes, and probably at least one additional gene can be obtained from a set of triplicate genes. Lindstrom (1929), East and Hayes (1911), Bach (1920), and Demerec (1923) have also studied the genetics of albino seedlings.

The factor for albino seedlings in the stock used was the independently inherited $w_{2}$.

Experimental Procedure.-Seeds known to segregate the albino type, $w_{2} w_{2}$, were planted in the greenhouse, where conditions of growth were kept as nearly uniform as possible throughout the series of experiments. The day before the plants were to be placed in the respiration chamber, the seedlings were transplanted to small glass vials containing pure quartz sand and sterile nutrient solution. ${ }^{2}$ Plants from one

1 Received for publication December 3, 1934.

Paper from the Department of Botany, University of Michigan, no. 495.

During the time that these experiments were in progress, the author was holding an appointment to the F. C. and Susan Newcombe Fellowship in Plant Physiology, in the Department of Botany at the University of Michigan. This opportunity is taken to thank the Department for awarding the Fellowship, and for helpful suggestions and criticisms.

2 The nutrient solution used was the same as that used by Spoehr and McGee (1923) in their studies of the effect of amino acids and sugars on respiratory rate. The exact composition of this solution is as follows: Four stock solutions were made up. Number $1-3 \mathrm{~g}$. calcium sulphate $\left(\mathrm{CaSO}_{4}\right)$ dissolved in 31 . of water. Number $2-6$ g. magnesium sulphate $\left(\mathrm{MgSO}_{4} 7 \mathrm{H}_{2} \mathrm{O}\right)$ in 1 l. of water. Number $3-\mathbf{3}$ g. soluble ferric phosphate (a combination of iron phosphate and sodium citrate) in 1 1. of water. Number 4-12 g. potassium chloride (KCl) in 11 . of water. The complete solution was to two weeks old were used. At this stage the green and the albino seedlings were of approximately the same size, both displaying a well developed leaf surface.

Before the plants were placed in the respiration chamber, the sand in each vial was moistened with additional nutrient solution, and the surface of the sand covered with paraffin. The paraffin covering prevented evaporation, and made it impossible for any carbon dioxide which might have been given off in root respiration, or by the respiration of microorganisms clinging to the roots, to influence the composition of the gas in the chamber. The paraffin used for this purpose melted at $42-45^{\circ} \mathrm{C}$., and when poured on the sand was at a temperature just high enough to keep it in a liquid condition. The plants were uninjured by paraffin of this temperature. At the end of each experiment the seedlings were cut off at the surface of the paraffin and dried at a temperature of $98^{\circ} \mathrm{C}$. for twenty-four hours, cooled in a desiccator, and weighed.

Twelve-inch soda-lime towers made very satisfactory respiration chambers for corn seedlings. Each tower conveniently contained three plants, leaving very little excess space. The base of each tower was weighted with sand, the surface of which was covered with paraffin, so that the entire chamber could be submerged in the bath and still maintain a firm, upright position.

For a constant temperature bath, an ordinary greenhouse aquarium, $25 \times 15 \times 15$ inches was used. This was large enough to contain five of the plant chambers, so that comparative experiments could be conducted under strictly comparable conditions. The aquarium was filled with distilled water, kept at a constant temperature of $30^{\circ} \mathrm{C}$. by means of an electric heater controlled by a thermostat. The water was kept in circulation by a stirring apparatus driven by an electric motor.

The interior of the bath was lighted by two 100watt frosted bulbs placed on opposite sides of the aquarium, and in such a position that the plants received a maximum amount of light. The light rays were concentrated on the chambers by means of concave mirrors. To keep certain plants in darkness, the chambers containing them were covered with made by mixing $30 \mathrm{ml}$. of solution 1 with $10 \mathrm{ml}$. of solution 2 and $10 \mathrm{ml}$. of solution 4 . The mixture was then diluted to $200 \mathrm{ml}$., and to this, $40 \mathrm{ml}$. of solution 3 was added. The solutions were sterilized separately by heating in the autoclave for one-half hour at 15 pounds pressure. When a solution containing nitrogen was desired, calcium nitrate $\left(\mathrm{Ca}\left(\mathrm{NO}_{3}\right)_{2} 4 \mathrm{H}_{2} \mathrm{O}\right)$ was substituted for the calcium sulphate in solution 1.

[The Journal for May (23: 309-379) was issued July 14, 1936.] 
black paper which had previously been soaked in melted paraffin and allowed to harden in the shape of the chamber.

A temperature of $30^{\circ} \mathrm{C}$. was used for the experiments because it was impossible to keep the bath at a lower temperature without artificial cooling. As corn thrives at relatively high temperatures, this proved to be satisfactory. At the end of the experiments the plants were still in good condition.

The apparatus used was of a modified Pettenkoffer type. Carbon dioxide-free gas was drawn into the plant chamber, and the carbon dioxide in the gas drawn out of the chamber was collected and measured by means of a system consisting of two tubes of calcium chloride and a glass-stoppered U-tube containing "ascarite." Four-inch U-tubes with hollow glass stoppers were used to hold the ascarite.
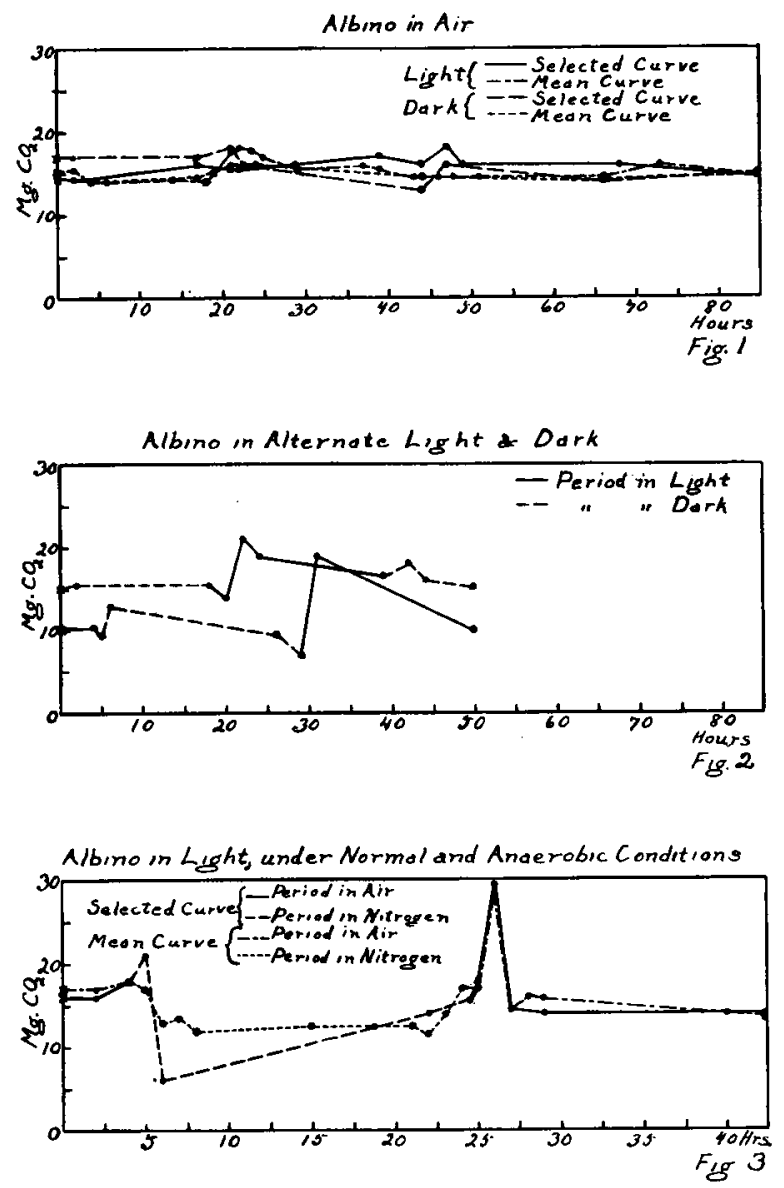

The stoppers were so constructed that the passage of gas was possible only when the small hole in the side was turned in a position coincident with the opening in the side arm of the tube. Two tubes were used alternately in each system, so that the flow of gas needed to be closed off for but a short time while the tubes were being exchanged. Stopcocks in the system, on either side of the tube of ascarite, were closed to prevent leakage while the exchange was being made. During the time that one tube was being weighed, the other was absorbing gas, and consequently the flow could be maintained with sufficient constancy to prevent the accumulation of carbon dioxide in the plant chamber. The U-tubes containing ascarite were very convenient to handle, and small increases in weight could be accurately detected. Consequently, the amount of carbon dioxide given off by a relatively small amount of plant material could be measured at short intervals.

A U-tube containing calcium chloride was placed on either side of the tube of ascarite to absorb any water vapor from the stream of gas. A bottle containing a solution of barium hydroxide was placed between the second calcium chloride tube and the safety bottle connected with the aspirator. As long as the barium hydroxide solution remained clear, it was evident that absorption of carbon dioxide by the ascarite had been complete.

At the beginning of an experiment, air, from which all carbon dioxide had been removed by passage through a tower of soda lime and a bottle of concentrated barium hydroxide solution, was drawn through the apparatus for approximately two hours before any readings were taken, to replace the gas originally present in the plant chamber with carbon dioxide-free gas. At this time a freshly weighed tube of ascarite was inserted in the srstem. The gas from the plant chamber was nassed over the ascarite slowly, at a constant rate regulated by the aspirator.

At first, a few readings were taken at hourly or two-hourly intervals. Later in the experiment a single tube could be left in the system for a longer period of time, and the average hourly rate calculated. Control experiments to determine the normal rate of respiration were usually allowed to run for from seventy-two to eighty-five hours; others, usually for shorter periods.

Plants from seven to twelve days old, counting from the first appearance of the plants above the soil, were used in these experiments. In handling the seedlings, care was taken to avoid injury.

REsults.-In all the graphs the number of hours for which the experiment was continued are shown on the abscissa, and the number of milligrams of carbon dioxide produced per hour per gram of dry leaf material are represented on the ordinate.

Six experiments were conducted with albino seedlings in light. Figure 1 shows the result of a single typical experiment, and the mean of all six experiments.

Three experiments were conducted with albino seedlings which were supplied with air, but kept in total darkness. These results are also included in figure 1. A graph is shown for a single typical experiment, and the mean of all three experiments. By comparison of the curves it will be observed that there is very little difference between the rates of respiration in light and in darkness.

Figure 6 shows two curves for the rate of respiration of green plants of the same age and parent stock 
as the albinos from which figure 1 was obtained. These curves are shown separately because one of the experiments was started at six in the evening, after the plants had had a full day for photosynthesis, and the other was started at eleven in the morning. All experiments with green plants were conducted in the dark. A comparison of figures 1 and 6 indicates that there is but little difference in the respective respiratory rates of green and albino seedlings.

Figure 2 shows the results of two experiments to determine the influence of alternate exposure to light and darkness on the respiratory rate of albino seedlings. Only the albinos were suitable for this type of experiment, as they have no photosynthetic activity to mask their carbon dioxide production in light. These results seem to give some support to Van der Paauw's (1932) belief ${ }^{3}$ in a so-called "plasmogenous" influence of light on rate of respiration, although the stimulation continues for but a short period after the exposure of the plants to light, following a period in darkness.

Figure 4 shows the respiratory curves obtained by feeding different sugars to albino seedlings from which the endosperm had been removed. Maltose, dextrose, and sucrose, respectively, were added in equal amounts to the nutrient solution with which the plants were watered. A control experiment, in which seedlings were supplied with nutrient solution, but no sugar, was conducted at the same time. The curves showing the results of feeding sugars are from individual experiments. Two controls are shown, one from an individual experiment, and one mean control obtained by averaging the results of four such experiments. Three milliliters of a 0.2 per cent solution of the sugar were supplied to each plant, and as the plant was also supplied with $2 \mathrm{ml}$. of nutrient solution, the plants were actually supplied with five milliliters of solution containing $0.006 \mathrm{~g}$. of sugar, or $0.018 \mathrm{~g}$. of sugar for the three plants in the chamber. The endosperm of the corn seedling can be readily removed without injuring the tissues of the plant.

Figure 5 shows the results obtained by feeding different concentrations of maltose to albino seedlings, and figure 7 , the influence of maltose and dextrose on the respiratory rate of green seedlings. With exception of the mean control, all of these curves are from individual experiments. In these experiments, $3 \mathrm{ml}$. of sugar solution of the required concentration was supplied to each plant, along with $2 \mathrm{ml}$. of nutrient solution. Thus, the addition of a 0.2 per cent sugar solution actually means that the plants were supplied with $0.006 \mathrm{~g}$. of sugar per plant, in $5 \mathrm{ml}$. of water. Likewise, $3 \mathrm{ml}$. of a 0.3 per cent sugar solution is equivalent to $0.009 \mathrm{~g}$. of sugar per plant in $5 \mathrm{ml}$. of water, and 0.5 per cent is equivalent to $0.015 \mathrm{~g}$. of sugar in $5 \mathrm{ml}$.

${ }^{3}$ Van der Paauw measured the rate of respiration of Hormidium before, during, and after exposure to light in a carbon dioxide-free vessel, and obtained an increase after exposure which was believed to be caused by a "plasmogenous" influence of light, an "ergastogenous" influence having been ruled out by the absence of carbon dioxide for photosynthesis.
An analysis of these graphs reveals that whereas all of the sugars which were tested caused an increase in respiratory rate, over and above that of plants under conditions of carbohydrate starvation, maltose brings about this increase in a shorter time than either dextrose or sucrose. In the green seedlings, dextrose was nearly as effective as maltose. These results differ somewhat from those of other investigators, but seem quite reasonable in light of the fact that the experiments were conducted with young
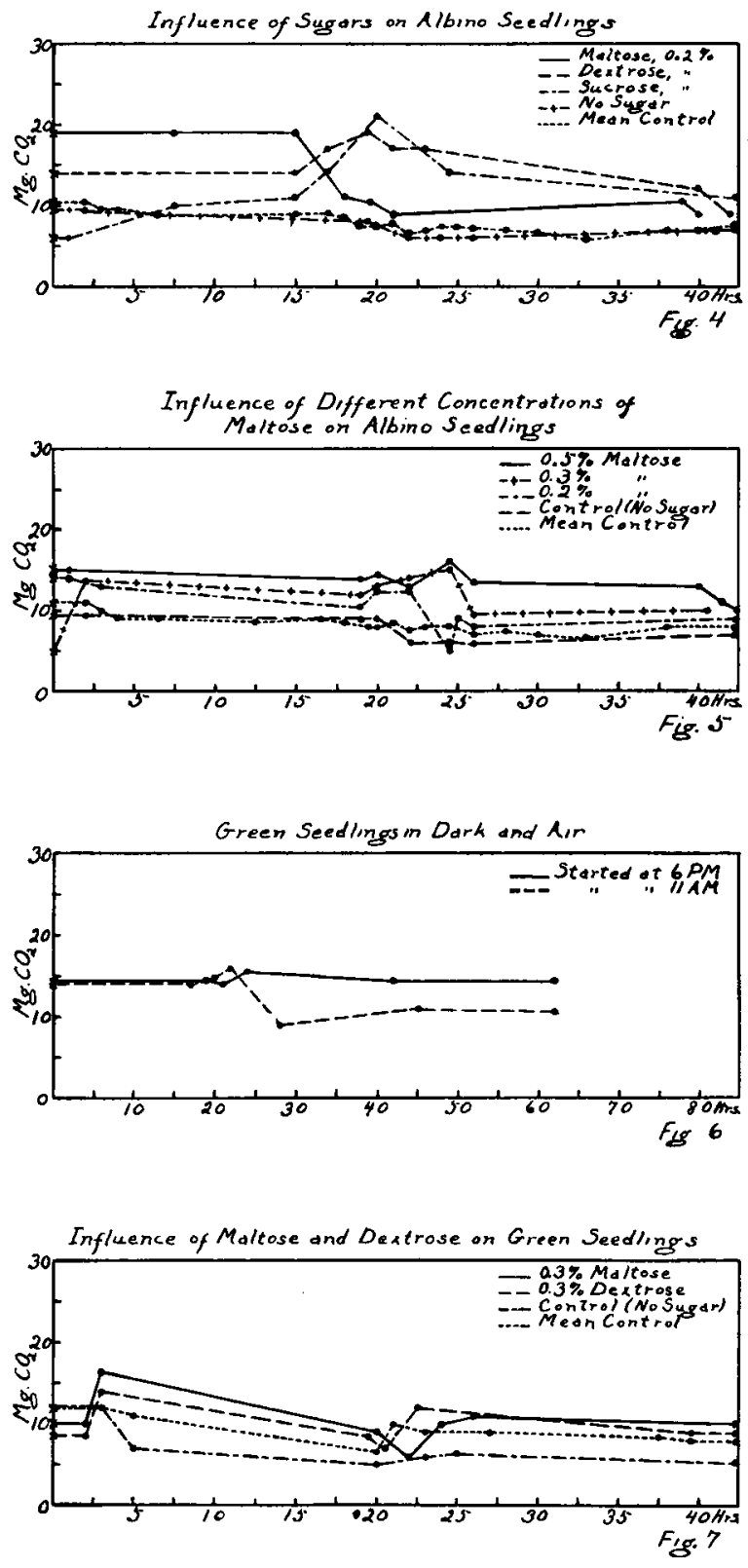

seedlings, wholly or partially dependent on the hydrolywis products of the starch in the endosperm for their supply of carbohydrates. As maltose is known to be an important intermediate in the hydrolysis of starch, seedlings of this type would in all probability be well adapted for its use. 
The results of experiments with feeding different concentrations of maltose to the albino seedlings indicate that an increase in sugar concentration prolongs the period of stimulation, but does not result in an increased carbon dioxide production per unit of time.

At the end of each of the experiments with feeding sugars, the residue in the vials was tested for hexoses, qualitatively, by the colorimetric method of Foulger (1932), and quantitatively by the method of Hagedorn and Jensen (1923). The Foulger test, with the reagent containing urea, which is sensitive to 0.5 $\mathrm{mg}$. as the lower limit of concentration, was negative in all instances, although the Hagedorn-Jensen test gave a slight reaction, indicating the presence of about $0.35 \mathrm{mg}$. of reducing substance, calculated as glucose. A comparison of the quantity of carbon which was supplied in the form of carbohydrate, with that given off as carbon dioxide, indicates that a fairly large proportion of the carbon must have come from the plant itself, probably from protein. By subtracting the amount of carbon given off as carbon dioxide by the control, which was not supplied with carbohydrates, from that given off by similar plants that were supplied with a known weight of sugar, the difference was found to be roughly equivalent to the amount of carbon supplied to the plants as sugar.

Figure 3 shows the influence of anaerobic conditions upon the rate of respiration of albino seedlings, kept in the light. These experiments were designed to determine whether or not the increase in respiratory rate when air was reintroduced following a period of anaerobiosis (reported previously for other plants by Maquenne, 1894a, 1894b; Palladin, 1903; Blackman and Parija, 1928) would occur in corn seedlings.

In experiments designed to reveal this phenomenon, the normal rate of respiration was measured for about twenty-four hours in air, and at the end of that time the air in the plant chamber was replaced by pure nitrogen. ${ }^{4}$ After about twenty-four hours of anaerobiosis, carbon dioxide-free air was again introduced and a definite increase in respiratory rate followed almost immediately. Figure 3 shows the result of a single experiment, and a mean curve obtained by averaging the results of two experiments. In these experiments, hourly readings were taken for

4 Commercial nitrogen that had been passed through chromous chloride to remove all traces of oxygen, and through concentrated alkali to remove carbon dioxide. When passed through a tube containing yellow phosphorus, this gas caused no fuming of the phosphorus. as many hours before and after the exchange of gases as was necessary. The experiments were conducted in light, so that any effect of darkness in causing the accumulation of amino acids in the plant could not be confused with the effects of anaerobic conditions.

Spoehr and McCree (1923) have found that an increase in amino nitrogen in the leaf brings about an increase in respiratory rate, and, as amino nitrogen has been known to accumulate under anaerobic conditions, it seemed possible that this increase in respiration following anaerobiosis might be brought about by the stimulatory effect of amino acids accumulated in the plant. However, this increase in rate of respiration was found in the albino without an accompanying increase in amino nitrogen content; the results of amino nitrogen analysis are to be published in a second paper. It appears, therefore, that some other factor must be responsible for the increase in production of carbon dioxide.

\section{SUMMARY}

The respiratory rates of normal green and albino corn seedlings were compared, and found to be practically identical under normal conditions. The apparatus used was of the Pettenkoffer type, weighed tubes of "ascarite" serving to absorb the carbon dioxide given off by the plants. The number of milligrams of carbon dioxide given off per hour, per gram dry weight of leaf material, was taken as a measure of rate of respiration.

Exposure to light or darkness over long periods of time was found to have no particular influence on the respiratory rate of the albino. However, if albino plants were suddenly exposed to light, after a period in darkness, an increase in the amount of carbon dioxide given off per unit of time was immediately noted. Likewise, a definite increase in rate of respiration was observed when air was reintroduced after albino seedlings had been subjected to a period of anaerobiosis in the light. The plants were placed under anaerobic conditions by substituting an atmosphere of nitrogen for the air in the plant chamber.

When supplied in nutrient solution to seedlings from which the endosperm had been removed, maltose was found to be most readily available, as measured by increased respiratory rate. Dextrose and sucrose also caused an increase, but required a longer period to bring about the change.

Department of Botany,

UNiversity OF MichigaN

LITERATURE CITED

Васн, S. 1920. Zweierlei Weisslinge bei Mais. Zeitschr. Pflanzenzüch. $7: 238-241$.

Blackman, F. F., And P. PariJa. 1928. Analytical studies in plant respiration. II. The respiration of apples in nitrogen and its relation to respiration in air. Proc. Roy. Soc. London B 103: 446-491.

Demerec, M. 1923. Inheritance of white seedlings in maize. Genetics 8: 561-593.
EAst, E. M., AND H. K. Hayes. 1911. Inheritance in maize. Connecticut Agr. Exp. Sta. Bull. 167.

Emerson, R. A. 1912. The inheritance of certain forms of chlorophyll reduction in corn leaves. Nebraska Agr. Exp. Sta. 25th Annual Rept. 89-105.

Foulger, J. H. 1932. Two new color tests for hexoses. Jour. Biol. Chem. 99: 207-209. 
Hagedorn, H. C., and B. N. Jexsen. 1923. Mikrobestimmung des Blutzuckers mittels Ferricyanide. Biochem. Zeitschr. 135: 46-58.

Lindstrom, E. W. 1924. Complementary genes for chlorophyll development in maize and their linkage relations. Genetics 9: 305-326.

Maquenne, L. 1894a. Sur la respiration des feuilles. Compt. Rend. Acad. Sci. Paris 119: 100-102. - 1894b. Sur le mécanisme de la respiration végétale. Compt. Rend. Acad. Sci. Paris 119: 697699.
Matsuura, H. 1929. A Bibliographical Monograph on Plant Genetics. Tokyo.

PaAUW, F. VAN DER. 1932. The indirect action of external factors on photosynthesis. Rec. Trav. Bot. Neerland. $29: 497-619$.

Palladin, W. 1903. Ueber normale und intramolekulare Atmung der einzelligen Alge Chlorothecium saccharophilum. Centralbl. Bakt. II, 11: 146-153.

Spoemr, H. A., AND J. M. McGee. 1923. Studies in plant respiration and photosynthesis. Carnegie Inst. Washington Publ. 325: 1-75.

\section{STUDIES IN FLORAL ANATOMY. III. AN INTERPRETATION OF THE GYNAECEUM IN THE PRIMULACEAE ${ }^{1}$}

\section{Jean Dickson}

UP то the present time there has been considerable controversy as to the exact structure of the primulaceous gynaeceum, and, possibly on account of its somewhat indeterminate vascular origin, there are few complete descriptions. The general supposition is that the gynaeceum consists of 5 fused carpels, the margins of which have, during the process of evolution, become detached and now appear as a free central placental column upon which the ovules are situated, but, as Rendle (1925) points out, "The ovary arises as a ring on the floral axis, so that its development affords as little evidence as does the structure of the adult pistil for the existence of 5 carpels." It is hoped that the following descriptions may throw some light upon the subject. The descriptions are based upon a study of complete series of microtome sections, at various stages of development of the flower, in each case.

The grateful thanks of the writer are due to Dr. Helen Bancroft for much valuable advice and helpful criticism, and to Professor R. S. Troup, Imperial Forestry Institute, Oxford, for the use of laboratory and apparatus.

DESCRIPTION OF THE FLORAL ANATOMY OF SELECTED PRIMULACEOUS FORMS.-Lysimachia vulgaris L.-The stele in the peduncle consists of a small cylinder of vascular tissue. As soon as the peduncle increases in diameter at the base of the flower, the cylinder likewise increases rapidly and gives off 10 strands which move out into the region of the sepals (fig. I, 1-3). These do not, however, solely represent the strands of the calyx; the bundles are of an extremely composite nature, for 5 consist of sepal midrib plus the fused laterals of two adjoining petals, ${ }^{2}$ and the alter-

1 Received for publication February 23, 1935.

2 "Having lost their capacity to function reproductively, the members of this whorl assumed, or reverted to, a more typically foliar condition in that the corresponding bundles, originally (as typically in members of the androecium) unbranched, now showed pinnate branching, the midvein alone entering the sterile staminal member as it became exserted, the lateral branches continuing their upward course into the free lobes of the corolla (Samolus ....)."

"In certain genera these staminodes became further reduced in size, and destitute of vascular tissue, the nating 5 consist of a pair of sepal laterals, petal midrib, petal-stamen and carpel midrib. This structure of the bundles is apparent as the individual supplies slowly separate from the primary cords (fig. I, 3).

The remnants of the primary central stele form the marginal (placental) strands of the carpels. These strands are typically indefinite in shape and number, but this is accounted for by the fact that whereas in some individuals the marginal strands of adjacent carpels may arise as one strand, in others they may arise separately, and frequently both conditions are present in the same individual.

It is to be noted that in this plant each placental strand of a carpel fuses laterally with one from a neighboring carpel (fig. I, 2-4), and it will be seen from the accompanying diagrams that the carpel

ante-sepalous bundles giving rise as before to a pair of laterals but ceasing to be prolonged into the central strand. ..."

"A further stage ... has produced the type ..., in which the ante-sepalous stamens are no longer developed as separate structures of characteristic form. Nevertheless the corresponding bundles persist, but they are no longer prolonged above the level of origin of the lateral branches. ..."

By these statements Saunders (1934) indicates that in her opinion the bundles here termed "fused laterals of adjoining petals" consist entirely of strands allotted to the ante-sepalous stamen whorl which in the Primulaceae is now practically nonexistent. To the present writer it seems possible that these bundles represent both petallaterals and $a$ stamen strand, and that except in cases where definite stamen strands are produced, e.g., Samolus, there is no conclusive evidence either one way or the other.

The marginal strands of a petal need not necessarily be derived as branches of the midribs, but they may arise directly from the floral axis, in which case the ante-sepalous stamen bundles may run up the corolla tube in connection with the petal-laterals. This point is very clearly demonstrated in Daphne mezereum (Thymeliaceae). Here the 8 bundles of the 4 -lobed perianth arise from the axis, each also bearing a stamen strand. Four form the midribs of the parianth lobes and the alternate 4, after the separation of the stamens, divide in exactly the same way as those of Samolus, although in this case there is no reduction in the function of the stamens. 